\title{
Rapid Prediction of Possible Inhibitors for SARS-CoV-2 Main Protease using Docking and FPL Simulations
}

\author{
Son Tung Ngo, ${ }^{a *}{ }^{*}$ Khanh B. Vu, ${ }^{\text {cd }}$ T. Ngoc Han Pham, e Le Thi Thuy Huong, fg Pham Minh Quan, fg Linh \\ Hoang Tran, dh Nguyen Thanh Tung, fi Van V. Vu,j Trung Hai Nguyen ${ }^{\mathrm{ab}}$ \\ aLaboratory of Theoretical and Computational Biophysics, Ton Duc Thang University, Ho Chi Minh City 700000, \\ Vietnam \\ bFaculty of Applied Sciences, Ton Duc Thang University, Ho Chi Minh City 700000, Vietnam \\ cSchool of Biotechnology, International University, Ho Chi Minh City 700000, Vietnam \\ dVietnam National University, Ho Chi Minh City, Vietnam
}

eFaculty of Pharmacy, Ton Duc Thang University, Ho Chi Minh City 700000, Vietnam

${ }^{\mathrm{f}}$ Graduate University of Science and Technology, Vietnam Academy of Science and Technology, Hanoi 100000, Vietnam gInstitute of Natural Products Chemistry, Vietnam Academy of Science and Technology, Hanoi 100000, Vietnam

hFaculty of Civil Energeering, Ho Chi Minh University of Technology (HCMUT), Ho Chi Minh 700000, Vietnam

institute of Materials Science, Vietnam Academy of Science and Technology, Hanoi 100000, Vietnam

jNTT Hi-Tech Institute, Nguyen Tat Thanh University, Ho Chi Minh City 700000, Vietnam

\begin{abstract}
Appearance for the first time from Wuhan, China, the SARS-CoV-2 rapidly outbreaks worldwide and causes a serious global health issue. The effective treatment for SARSCoV-2 is still unavailable. Therefore, in this work, we have tried to rapidly predict a list of potential inhibitors for SARS-CoV-2 main protease (Mpro) using a combination of molecular docking and fast pulling of ligand (FPL) simulations. The approaches were initially validated over a set of eleven available inhibitors. Both Autodock Vina and FPL calculations adopted good consistent results with the respective experiment with correlation coefficients of $R_{\text {Dock }}=0.72 \pm$ 0.14 and $R_{\mathrm{W}}=-0.76 \pm 0.10$, respectively. The combined approaches were then utilized to predict possible inhibitors, which were selected from a ZINC15 sub-database, for SARSCoV-2 Mpro. Twenty compounds were suggested to be able to bind well to SARS-CoV-2 Mpro. The obtained results probably lead to enhance COVID-19 therapy.
\end{abstract}

\section{INTRODUCTION}

The novel coronavirus, named SARS-CoV-2 or 2019-nCoV, causes COVID-19 disease which is an ongoing global pandemic. First cases of COVID-19 infection were reported in Wuhan, Hubei, China in December 2019. ${ }^{1-3}$ The virus was found to be able to transmit from human to human. 4 Especially, It has been suggested that SARS-CoV-2 can transmit through airborne/aerosol since the virus was found to remain viable and infectious in such environment for more than three hours. 5 The novel coronavirus causes severe acute respiratory syndromes which have resulted in hundreds of thousands of deaths worldwide.6, 7 Moreover, the intermediate host is still undetected, although the original reservoir is indicated as the bat. ${ }^{8}$ Understanding the spread of the virus thus becomes more difficult. The current global health crisis caused by COVID-19 has called for urgent research and development of an efficient antiviral drug.

SARS-CoV-2 and SARS-CoV share about $82 \%$ similarity in their RNA genomes. The genomes of coronaviruses ranges from 26 to $32 \mathrm{~kb}$ in length. The viruses thus have the largest sequence among RNA virus.9, 10 There are more than 20 different proteins encoded by the genomes of the SARS-CoV2. In particular, the SARS-CoV-2 main protease (Mpro) is known as one of the most critical viral proteins. It should be noted that the SARS-CoV-2 Mpro adopts more than $96 \%$ similarity to the SARS-CoV Mpro. During the viral translation, the SARS-CoV-2 Mpro cleaves eleven polyproteins to polypeptides, which are necessary for the transcription and replication of the virus. ${ }^{10}$ The SARS-CoV-2 Mpro is selected as one of the most potent drug targets for inhibiting the viral proliferations. ${ }^{11} 12$ Thefore, numerous studies have been conducted using experimental and computational approaches in order to search for potential small-molecule inhibitors that can effectively block the activity of this protease. ${ }^{11-17}$

It should be noted that computer-aided drug design (CADD) can significantly reduce the time and cost for developing a therapy. ${ }^{18,19}$ In the CADD approach, the ligandbinding free energy $\Delta G$ can be calculated through MD simulations. This metric is linked with the experiment through formula $\Delta G_{\text {bind }}=R T \ln \left(k_{\mathrm{i}}\right)$, where $k_{\mathrm{i}}$ is inhibition constant, $T$ is absolute temperature, and $R$ is gas constant. In some cases, $\mathrm{IC}_{50}$ is assumed to be equal to $k_{\mathrm{i}}$ in order to estimate the experimental binding free energy $\Delta G_{\mathrm{EXP}} \cdot{ }^{14}, 20,21$ Because the metric reveals the binding mechanism between biomolecules, ${ }^{18}$ accurate and precise investigation of the ligand-binding free energy is tremendously critical for 
searching potential inhibitors. ${ }^{22}$ In this work, the potential candidates from $\mathrm{ZINC}_{15}$ in man compounds, ${ }^{23}$ which can bind to the SARS-CoV-2 Mpro, were screened using combined approaches of molecular docking and FPL simulations. It should be noted that this combined computational scheme was previously validated by testing on eleven available inhibitors whose calculated binding free energies were in good agreement with respect to experiments. ${ }^{11-13}$ Our present study suggested that twenty compounds were able to bind with high affinity to SARS-CoV-2 Mpro. These compounds can become promising leads for developing drugs against the COVID-19 disease.

\section{MATERIALS \& METHODS}

\section{Structure of Ligands and SARS-CoV-2 Mpro}

Three-dimensional structures of SARS-COV-2 Mpro was obtained from the Protein Data Bank with the identify of $6 \mathrm{Y}_{2} \mathrm{~F} .{ }^{11}$ Ligand structures were taken from the $\mathrm{ZINC}_{15}$ in man only and the PubChem database. ${ }^{23}, 24$

\section{Molecular Docking Simulations}

The ligands were docked to the SARS-CoV-2 Mpro by using the Autodock Vina version 1.1 package. ${ }^{25}$ The parameter of the docking approach was chosen according to the previous study, ${ }^{14,26}$ in which the parameter of exhaustiveness was set to the default value of 8 . The best docking conformations were chosen as having the largest binding affinity. The grid center was designated as the center of mass of compound $\alpha$ ketoamide $13 \mathbf{b}$. ${ }^{11}$ The grid size was chosen as $2.6 \times 2.6 \times 2.6$ nm according to the recent work. ${ }^{14}$

\section{Fast Pulling of Ligand (FPL) Simulations}

GROMACS version 5.1. $5^{27}$ was utilized to simulate unbinding process of a ligand pulled out of the binding cavity of the SARS-CoV-2 Mpro. The protein and ions were parameterized using the Amber99SB-ILDN force field. ${ }^{28}$ The $\mathrm{TIP}_{3} \mathrm{P}$ model was utilized for water molecules. ${ }^{29}$ The general Amber force field (GAFF) ${ }^{30}$ was used to represent the ligand via AmberTools18. ${ }^{31}$ The ACPYPE ${ }^{2}$ protocol was used to transform AMBER to GROMACS formats. In particular, the ligand atomic charges were fitted using the restrained electrostatic potential (RESP) method 33 which is based on DFT calculations with B 3 LYP functional and $6-31 \mathrm{G}(\mathrm{d}, \mathrm{p})$ basis set. It should be noted that the combination of the force fields was preferred since it is one of the most solution for free energy assessment. 34,35

The complex SARS-CoV-2 + inhibitor was initially inserted into a rectangular $\mathrm{PBC}$ (periodic boundary conditions) box with a size of $9.83 \times 5.92 \times 8.70 \mathrm{~nm}$ (Figure 1 ), similarly to the recent work. ${ }^{14}$ The complex system thus consists of more than 50 ooo atoms including the SARS-CoV-2 Mpro, ligand, water molecules, and counterbalanced ions $\mathrm{Na}^{+}$. The solvated SARS-CoV-2 Mpro + inhibitor system was firstly minimized via the steepest descent approach. The 0.1 ns of NVT and 2.0 ns of NPT imitations were then followed to relax the complexed system, in which the SARS-CoV-2 Mpro $C_{\alpha}$ atoms were positionally restrained using a harmonic potential. Finally, the ligand was forced to move out of the SARS-CoV-2 Mpro active site by applying an external harmonic force with a pulling speed of $k=0.005 \mathrm{~nm} \mathrm{ps}^{-1}$ and a spring constant of $v=600 \mathrm{~kJ} \mathrm{~mol}^{-1} \mathrm{~nm}^{-2}$. The pulling speed and spring constant were chosen to be the same as in the previous works. ${ }^{14}, 36,37$ During steered-MD simulations, the ligand displacement and the applied pulling force were recorded every o.1 ps that would be used to estimate the ligand binding affinity. ${ }^{36}$ Totally, the FPL calculations were independently performed 8 times to guarantee the sufficient sampling.

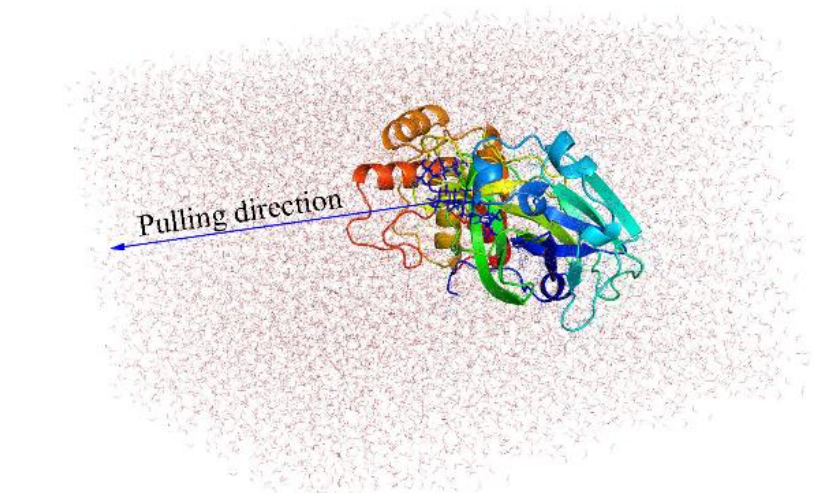

Figure 1. Computational conformation of the SARS-CoV-2 Mpro + periandrin $V$.

\section{Analyzed Tools}

The ligand protonation state was predicted by using the Chemicalize tools (www.chemicalize.com), a website application of the ChemAxon. The error of computations was estimated via 1000 rounds of the bootstrapping method. $3^{8}$

\section{RESULTS AND DISCUSSION}

\section{Molecular Docking Simulation}

Molecular docking simulations are normally employed to probe the binding affinity between ligands and proteins. Autodock Vina ${ }^{25}$, an open-source docking protocol, is widely used for this purpose. The binding affinity between the ligands and the SARS-CoV-2 Mpro was efficiently estimated using Autodock Vina. 25 The calculated binding affinity (Table 1) is strongly correlated with experimental binding affinity with an estimated correlation coefficient of $R_{\text {Dock }}=0.72 \pm$ 0.14 (cf. Table 1 and Figure 2). ${ }^{11-13}$ Moreover, the root-meansquare error (RMSE) with respect to experiment was estimated as $R M S E=2.42 \pm 0.22 \mathrm{kcal} \mathrm{mol}^{-1}$ (Figure 2). ${ }^{11-13} \mathrm{It}$ should be noted that the obtained results are consistent with the recent work which reported the corresponding values of $R_{\text {Dock }}=0.82 \pm 0.08$ and $R M S E=2.28 \pm 0.21 \mathrm{kcal} \mathrm{mol}^{-1} .39$

Table 1. The obtained values of the docking simulations.

\begin{tabular}{llll}
\hline$N^{0}$ & Name & $\Delta \mathbf{G}_{\text {Dock }^{a}}$ & $\Delta \mathbf{G}_{\mathbf{E X P}}{ }^{\text {b }}$ \\
\hline 1 & $11 \mathrm{r}$ & $-6.5^{\mathrm{c}}$ & -9.23 \\
2 & $13 \mathrm{a}$ & $-6.5^{\mathrm{c}}$ & -7.70 \\
3 & $13 \mathrm{~b}$ & $-6.3^{\mathrm{c}}$ & -8.45 \\
4 & $11 \mathrm{a}$ & -6.8 & -9.96 \\
5 & $11 \mathrm{~b}$ & -7.0 & -10.13 \\
6 & Carmofur & -5.7 & -7.86 \\
7 & Disulfiram & -3.8 & -6.89 \\
8 & Ebselen & -5.6 & -8.45 \\
9 & PX-12 & -3.8 & -6.39 \\
10 & Shikonin & -6.1 & -6.58 \\
11 & Tideglusib & -6.6 & -7.95 \\
\hline
\end{tabular}

aThe docking affinity was gained using the Autodock Vina package. ${ }^{b}$ The experimental binding free energy $\Delta G_{\mathrm{EXP}}$ was roughly computed via the reported $\mathrm{IC}_{5} \mathrm{O}^{11-13}$ with a supposition that the IC 50 value is equal to the inhibition constant $k_{\mathrm{i}}$. ${ }^{\text {eThe }}$ 
values were reported in the previous work. ${ }^{14}$ The unit is in kcal $\mathrm{mol}^{-1}$.

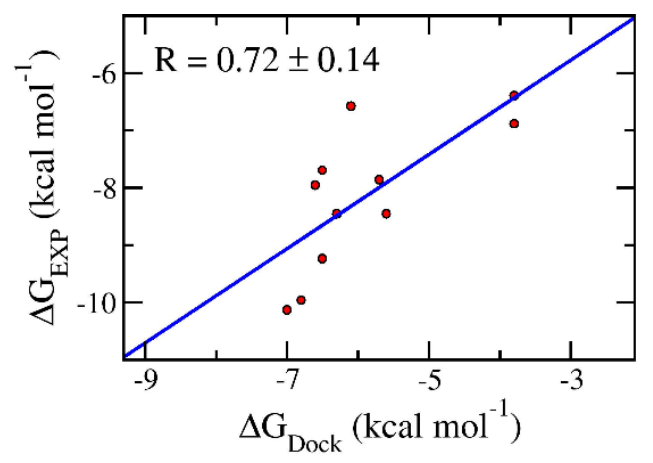

Figure 2. Correlation between molecular docking and experiment. The error of the correlation coefficient was determined via 1000 rounds of the bootstrapping method. $3^{8}$

The good docking performance for 11 ligands as shown above gives us the confidence to carry out docking calculations for 36090 compounds in $\mathrm{ZINC}_{15}$ in man only compounds using Autodock Vina package. ${ }^{25}$ However, the compound ZINCooo169876613 was skipped because it contains the element silicon for which the docking package has no parameters. The estimated binding free energies for 36089 compounds ranges from -1.8 to $-9.9 \mathrm{kcal} \mathrm{mol}^{-1}$ and have the median of $-5.72 \mathrm{kcal} \mathrm{mol}^{-1}$ and the standard deviation of $1.20 \mathrm{kcal} \mathrm{mol}^{-1}$. We selected one hundred compounds with binding affinity to the SARS-CoV-2 Mpro lower than -8.9 kcal $\mathrm{mol}^{-1}$ (Figure 3) for from further investigations using MD simulations. However, thirty-nine of them were discarded from the set since they are just different in protonation states of the same molecules. Overall, sixty-one compounds with two-dimensional interaction diagrams with SARS-CoV-2 Mpro (Table Si of the Supplementary - SI file) were investigated the unbinding progress via FPL simulations.

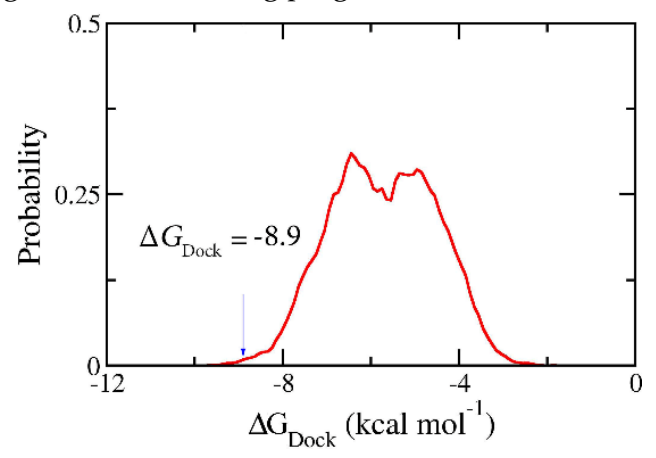

Figure 3. Distribution of the docking energy between 36089 $\mathrm{ZINC}_{15}$ in man only compounds and the SARS-CoV-2 Mpro. The results were gained using the Autodock Vina.

\section{Estimating Ligand Affinity using FPL Simulations}

Although, the docking protocol adopts appropriate results compared with experiments (Figure 2), ${ }^{11-13}$ lacking consideration of the receptor dynamics and limiting the number trial position of ligands may cause inaccurate prediction. A more accurate and precise method would be normally employed to refine the docking observation. ${ }^{21,40}$ Moreover, because the FPL calculation commonly offers accurate and precise results with an reasonable CPU time consumption..$^{41}$ Furthermore, it should be noted that FPL simulations were successfully used in the previous work ${ }^{14}$ to correctly rank the ligand-binding affinity of the $\alpha$-ketoamide 11r, 13a, and $1 \mathbf{1}^{\mathbf{1 1}}$ to the SARS-CoV-2 Mpro. The validated calculations were also performed over the additionally available inhibitors including 11a, 11b, carmofur, disulfiram, ebselen, $P X-12$, shikonin, and tideglusib. ${ }^{12}, 13$ The obtained results were shown in

Table 2 and Figure $S_{1}$ of the SI file. In particular, the mean pulling work $W$ of eleven inhibitors falls in the range from 16.5 \pm 1.7 to $94.6 \pm 5.0 \mathrm{kcal} \mathrm{mol}^{-1}$, giving a median of $47.2 \pm 8.6 \mathrm{kcal}$ $\mathrm{mol}^{-1}$. Besides that, the average of the rupture forces forms in the range from $321.2 \pm 26.5$ to $-884.2 \pm 36.5 \mathrm{pN}$, giving an average value of $530.2 \pm 62.6 \mathrm{pN}$. The calculated values are in good agreement with the respective experiments, ${ }^{11-13}$ because the correlation coefficient between the mean pulling work and experimental values is of $R_{\mathrm{W}}=-0.76 \pm 0.10$ (Figure 4). The computed error was estimated using 1000 rounds of the bootstrapping method. $3^{8}$ Furthermore, the sign of the correlation coefficient $R_{\mathrm{W}}$ implied that the ligand with a stronger binding affinity requires a larger pulling work to dissociate from the SARS-CoV-2 Mpro. Therefore, from linear regression we could estimate the relation between binding free energy $\Delta G_{\mathrm{FPL}}^{\mathrm{Pre}}$ and the pulling work as

$$
\Delta G_{\mathrm{FPL}}^{\mathrm{Pre}}=-0.056 * W-5.512
$$

The precision of the FPL estimation was evaluated by the RMSE with linear regression, giving $R M S E_{\mathrm{W}}=1.03 \pm 0.14$ $\mathrm{kcal} \mathrm{mol}^{-1}$. The small value of RMSE imply that the FPL simulations can discriminate ligands revealing similar binding free energies. The error was estimated by the standard deviation of 1000 bootstrap samples. $3^{8}$ Overall, the FPL calculations are effective protocol to evaluate the ligandbinding affinity of the SARS-CoV-2 Mpro with the suitable accuracy and precision.

Table 2. The obtained values of the FPL calculations.

\begin{tabular}{lllll} 
No $^{\mathrm{N}}$ & Name & $\boldsymbol{F}_{\mathbf{M a x}}{ }^{\mathrm{a}}$ & $\boldsymbol{W}^{\mathrm{b}}$ & $\Delta \mathbf{G}_{\mathbf{E X P}}{ }^{\mathrm{c}}$ \\
\hline 1 & $11 \mathrm{r}$ & $857.5 \pm 38.7^{\mathrm{d}}$ & $94.6 \pm 5.0^{\mathrm{e}}$ & -9.23 \\
2 & $13 \mathrm{a}$ & $496.0 \pm 32.5^{\mathrm{d}}$ & $43.3 \pm 3.9^{\mathrm{e}}$ & -7.70 \\
3 & $13 \mathrm{~b}$ & $884.2 \pm 36.5^{\mathrm{d}}$ & $91.9 \pm 3.6^{\mathrm{e}}$ & -8.45 \\
4 & $11 \mathrm{a}$ & $701.3 \pm 54.1$ & $70.7 \pm 5.9$ & -9.96 \\
5 & $11 \mathrm{~b}$ & $718.7 \pm 46.8$ & $74.3 \pm 4.4$ & -10.13 \\
6 & Carmofur & $421.5 \pm 23.9$ & $32.6 \pm 1.8$ & -7.86 \\
7 & Disulfiram & $371.3 \pm 20.3$ & $24.5 \pm 1.9$ & -6.89 \\
8 & Ebselen & $381.0 \pm 34.0$ & $23.5 \pm 2.5$ & -8.45 \\
9 & PX-12 & $321.3 \pm 26.5$ & $16.5 \pm 1.7$ & -6.39 \\
10 & Shikonin & $327.9 \pm 24.4$ & $21.2 \pm 2.1$ & -6.58 \\
11 & Tideglusib & $351.8 \pm 32.4$ & $26.3 \pm 2.4$ & -7.95 \\
\hline
\end{tabular}

aThe obtained value of the mean rupture force $\boldsymbol{F}_{\mathbf{M a x}}$ and bthe recorded metric of the pulling work $\boldsymbol{W}$. ${ }^{\text {cThe experimental }}$ binding free energy $\Delta G_{\text {EXP }}$ was coarsely estimated via the reported $\mathrm{IC}_{5 \mathrm{O}^{11-13}}$ with a supposition that the $\mathrm{IC}_{5 \mathrm{O}}$ value is equal to the inhibition constant $k_{\mathrm{i}}$. deThe values were reported in the previous work. ${ }^{14}$ The computed error was the standard error of the average. The unit is in $\mathrm{kcal} \mathrm{mol}^{-1}$. 


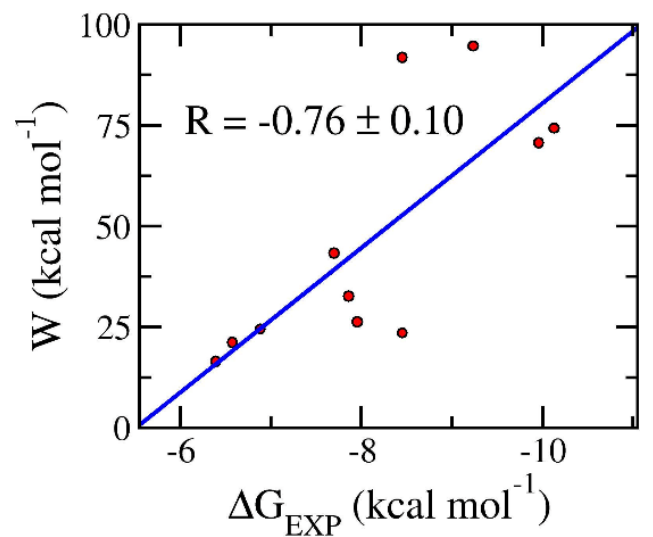

Figure 4. Correlation between the average of the pulling work $W$ and the binding free energy $\Delta G_{E X P}$ of the respective experiments. Computed values were obtained via the FPL simulations. Experimental metrics were roughly estimated via the reported $\mathrm{IC}_{5 \mathrm{O}^{11-13}}$ with a hypothesis that the $\mathrm{IC}_{50}$ value is equal to the inhibition constant $k_{i}$ in the recent publications. ${ }^{11-13}$ The linear regression between pulling work and the experiment is $W=-17.993 * \Delta G_{\mathrm{EXP}}-98.852$.
The FPL calculations were thus applied to evaluate the binding affinity of docking-top-lead compounds to the SARSCoV-2 Mpro, which consists of sixty-one compounds listing in Table 3 and Table S2 of the SI file. The mean rupture forces and mean pulling works were found to be diffused in the range from $389.5 \pm 20.9$ to $822.4 \pm 40.0 \mathrm{pN}$ and $32.9 \pm 2.6$ to $94.1 \pm$ $4.7 \mathrm{kcal} \mathrm{mol}^{-1}$, respectively. Particularly, the median of the corresponding metrics are of $574.5 \mathrm{pN}$ and $57.9 \mathrm{kcal} \mathrm{mol}^{-1}$, respectively. Moreover, the predicted binding free energies between ligands and the SARS-CoV-2 Mpro were calculate by using Eq. (1). The value $\Delta G_{\mathrm{FPL}}^{\mathrm{Pre}}$ was thus obtained and shown in Table 3 and Table S2 of the SI file. It may be argued that a ligand with estimated bining free energy, $\Delta G_{\mathrm{FPL}}^{\mathrm{Pre}}$, less than $9.00 \mathrm{kcal} \mathrm{mol}^{-1}$ may be able to inhibit the activity of the SARSCoV-2 Mpro. Therefore, we expect that twenty such compounds to be potential inhibitors for SARS-CoV-2 Mpro activity (Table 3) because of their strong binding affinity. In addition, it may argue that the other compounds, described in in Table S2 of the SI file, probably adopt less effects on the structure of SARS-CoV-2 Mpro.

Table 3. The obtained values of the docking and FPL simulations.

\begin{tabular}{|c|c|c|c|c|c|c|}
\hline $\mathrm{N}^{\mathrm{O}}$ & ZINC ID & Name & $\Delta \mathbf{G}_{\text {Dock }}{ }^{\mathrm{a}}$ & $F_{\text {Max }}{ }^{\text {b }}$ & $\boldsymbol{W}^{\mathrm{c}}$ & $\Delta G_{\mathrm{FPL}}^{\mathrm{Pre}_{\mathrm{d}}}$ \\
\hline 1 & ZINCooo256110404 & Periandrin V & -9.1 & $782.7 \pm 39.0$ & $94.1 \pm 4.7$ & -10.76 \\
\hline 2 & ZINCoooo85537131 & Penimocycline & -9.0 & $798.3 \pm 51.2$ & $92.8 \pm 7.0$ & -10.69 \\
\hline 3 & ZINCooo10o783644 & cis-p-Coumaroylcorosolic acid & -8.9 & $822.4 \pm 40.0$ & $89.5 \pm 4.1$ & -10.51 \\
\hline 4 & ZINCooo253527863 & Glycyrrhizin & $-9 \cdot 3$ & $598.4 \pm 43.2$ & $86.2 \pm 8.2$ & -10.32 \\
\hline 5 & ZINCooo256105139 & Uralsaponin B & $-9 \cdot 7$ & $690.6 \pm 33.7$ & $83.6 \pm 3.0$ & -10.17 \\
\hline 6 & ZINCooo10o783815 & 3-trans-Caffeoyltormentic acid & -8.9 & $731.8 \pm 53.0$ & $77 \cdot 5 \pm 4.1$ & -9.83 \\
\hline 7 & ZINCooooo4214527 & Triamcinolone Benetonide & -8.9 & $664.0 \pm 21.6$ & $74.8 \pm 2.3$ & -9.68 \\
\hline 8 & ZINCoooo28642721 & Sennidin A & -9.5 & $779 \cdot 7 \pm 58.8$ & $74 \pm 5.2$ & -9.64 \\
\hline 9 & ZINCooo10o78389o & 23-trans-p-Coumaroyloxytormentic acid & -9.2 & $566.7 \pm 15.1$ & $72.9 \pm 3.4$ & $-9 \cdot 58$ \\
\hline 10 & ZINCoooog8052857 & Evans Blue & -8.9 & $670.2 \pm 56.1$ & $72.7 \pm 6.8$ & $-9 \cdot 56$ \\
\hline 11 & ZINCooo10o783691 & Sanguisorbin B & -8.9 & $616.9 \pm 32.9$ & $71.6 \pm 3.2$ & -9.51 \\
\hline 12 & ZINCoooo95619992 & Licoricesaponin $C_{2}$ & -8.9 & $616.3 \pm 44.2$ & $69.9 \pm 7.0$ & -9.41 \\
\hline 13 & ZINCooo118937488 & Withangulatin A & -9.0 & $703.5 \pm 31.5$ & $68.5 \pm 3.7$ & -9.33 \\
\hline 14 & ZINCooo10078366o & trans-3-Feruloylcorosolic acid & -9.2 & $654.9 \pm 23 \cdot 3$ & $67 \cdot 3 \pm 2.5$ & -9.26 \\
\hline 15 & ZINCooo10o777487 & Physalin D & -8.9 & $682.3 \pm 32.9$ & $65.8 \pm 2.8$ & -9.18 \\
\hline 16 & ZINCooooo4879678 & Guamecycline & -9.6 & $565.2 \pm 24.8$ & $64.7 \pm 4.8$ & -9.12 \\
\hline 17 & ZINCooo150354128 & $\begin{array}{l}\text { Bis(4-methoxybenzoyl)-3a,29-dihydroxy- } \\
\text { 8-multifloren-7-one }\end{array}$ & -8.9 & $564.8 \pm 39.4$ & $63.8 \pm 3.1$ & -9.07 \\
\hline 18 & ZINCooooo4215464 & Cortisuzol & -9.2 & $579.3 \pm 38.9$ & $63.5 \pm 4.2$ & -9.05 \\
\hline 19 & ZINCooo100774273 & Rubroskyrin & -8.9 & $696.1 \pm 51.3$ & $62.9 \pm 5.1$ & -9.02 \\
\hline 20 & ZINCoooo73224787 & Tirilazad Mesylate & -9.1 & $573.8 \pm 46.7$ & $62.7 \pm 3.4$ & -9.01 \\
\hline
\end{tabular}

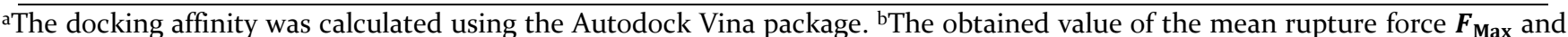
${ }^{c}$ the recorded metric of the pulling work $\boldsymbol{W}$. ${ }^{\mathrm{d}}$ The predicted binding free energy $\Delta G_{\mathrm{FPL}}^{\mathrm{Pre}}$ was attained using Eq. (1). The computed error was the standard error of the average. The unit of energy and force are in $\mathrm{kcal} \mathrm{mol}^{-1}$ and pN, respectively.

\section{CPU Time Consumption}

Each SARS-CoV-2 Mpro + inhibitor complex was simulated over 8 independent FPL simulations, which started from same initial conformation but different random velocity. One FPL trajectory includes $0.1 \mathrm{~ns}$ of NVT, $2.0 \mathrm{~ns}$ of NPT, and $0.5 \mathrm{~ns}$ of SMD simulations. $20.8 \mathrm{~ns}$ of MD simulations was thus performed to estimate the ligand-binding affinity of the SARSCoV-2 Mpro with 8 various FPL trajectories. It should be noted that one personal computer with AMD Ryzen 9 3950X CPU and RTX 206o Super acceleration can perform ca. 8o ns of MD simulation per day for the SARS-CoV-2 Mpro + inhibitor system. Therefore, the binding affinity of a ligand to the SARSCoV-2 Mpro is able to compute 8 times during ca. 6.24 hours. The low CPU requirement permits us to rapidly calculate the binding affinity of many ligands to the SARS-CoV-2 Mpro without any professional computing system. 


\section{CONCLUSIONS}

We have demonstrated that a combination of molecular docking using Autodock Vina and FPL simulations is able to efficiently estimate the binding affinity of a ligand to the SARS-CoV-2 Mpro. In particular, over eleven available inhibitors for preventing the activity of the SARS-CoV-2 Mpro, Autodock Vina formed a good consistent with the respective experiments. ${ }^{11-13}$ The correlation coefficient and RMSE are measured as $R_{\text {Dock }}=0.72 \pm 0.14$ and $R M S E=2.42 \pm 0.22$ kcal mol-1, respectively. Moreover, the FPL simulations also adopted results that is in good agreement with these experiments. ${ }^{11-13}$ The correlation coefficient and RMSE with linear regression are $R_{\mathrm{W}}=-0.76 \pm 0.10$ and $R M S E_{\mathrm{W}}=$ $1.03 \pm 0.14 \mathrm{kcal} \mathrm{mol}^{-1}$, respectively.

The combination of two approaches is thus employed to predict potential inhibitors for the SARS-CoV-2 Mpro. A shortlist consisting of sixty-one compounds was found after 36089 compounds were docked to the active site of the SARSCoV-2 Mpro. The obtained results were then refined by utilizing the FPL calculations. Twenty compounds were finally suggested that they are able to inhibit the activity of the SARSCoV-2 Mpro because they have low $\Delta G_{\mathrm{FPL}}^{\mathrm{Pre}}$, which is smaller than $-9.00 \mathrm{kcal} \mathrm{mol}^{-1}$. Further investigation using in vitro and/or in vivo studies should be carried out to validate the obtained results.

In addition, as discussed above, the requirement of CPU time is quite low. The combination of the Autodock Vina and FPL simulations are efficient way to rapid screening a large number of trial ligand for the SARS-CoV-2 Mpro. Especially, the computations can be carried out at home using an affordable PC with AMD CPU and Nvidia RTX GPU card acceleration.

\section{ASSOCIATED CONTENT}

\section{Supporting Information}

Supporting Information Available: The material is available free of charge via the Internet at http://pubs.acs.org.

\section{AUTHOR INFORMATION}

\section{Corresponding Author}

*Email: ngosontung@tdtu.edu.vn

\section{Author Contributions}

All authors contribute to the study and drafting the manuscript.

\section{Notes}

The authors declare no competing financial interests.

\section{ACKNOWLEDGMENT}

This work was supported by Vietnam National Foundation for Science \& Technology Development (NAFOSTED) grant \#104.99-2019.57.

\section{REFERENCES}

1. Huang, C. L.; Wang, Y. M.; Li, X. W.; Ren, L. L.; Zhao, J. P.; Hu, Y.; Zhang, L.; Fan, G. H.; Xu, J. Y.; Gu, X. Y.; Cheng, Z. S.; Yu, T.; Xia, J. A.; Wei, Y.; Wu, W. J.; Xie, X. L.; Yin, W.; Li, H.; Liu, M.; Xiao, Y.; Gao, H.; Guo, L.; Xie, J. G.; Wang, G. F.; Jiang, R. M.; Gao, Z. C.; Jin, Q.; Wang, J. W.; Cao, B., Clinical features of patients infected with 2019 novel coronavirus in Wuhan, China. Lancet 2020, 395 (10223), 497-506.

2. Wang, C.; Horby, P. W.; Hayden, F. G.; Gao, G. F., A novel coronavirus outbreak of global health concern. Lancet 2020, 395 (10223), 470-473.
3. Yu Wai, C.; Chin-Pang, Y.; Kwok-Yin, W., Prediction of the SARS-CoV-2 (2019-nCoV) 3C-like Protease (3CLpro) Structure: Virtual Screening Reveals Velpatasvir, Ledipasvir, and Other Drug Repurposing Candidates. F1000Res 2020, 9, 129.

4. Chan, J. F. W.; Yuan, S. F.; Kok, K. H.; To, K. K. W.; Chu, H.; Yang, J.; Xing, F. F.; Liu, J. L.; Yip, C. C. Y.; Poon, R. W. S.; Tsoi, H. W.; Lo, S. K. F.; Chan, K. H.; Poon, V. K. M.; Chan, W. M.; Ip, J. D.; Cai, J. P.; Cheng, V. C. C.; Chen, H. L.; Hui, C. K. M.; Yuen, K. Y., A Familial Cluster of Pneumonia Associated with the 2019 Novel Coronavirus Indicating Person-to-Person Transmission: a Study of a Family Cluster. Lancet 2020, 395 (10223), 514523.

5. van Doremalen, N.; Bushmaker, T.; Morris, D. H.; Holbrook, M. G.; Gamble, A.; Williamson, B. N.; Tamin, A.; Harcourt, J. L.; Thornburg, N. J.; Gerber, S. I.; Lloyd-Smith, J. O.; de Wit, E.; Munster, V. J., Aerosol and Surface Stability of SARSCoV-2 as Compared with SARS-CoV-1. N Engl J Med 2020.

6. WHO Coronavirus disease 2019 (COVID-19) Situation Report - 52 .

7. worldometrics COVID-19 Coronavirus Pandemic https://www.worldometers.info/coronavirus/.

$8 . \quad$ Zhou, P.; Yang, X.-L.; Wang, X.-G.; Hu, B.; Zhang, L.; Zhang, W.; Si, H.-R.; Zhu, Y.; Li, B.; Huang, C.-L.; Chen, H.-D.; Chen, J.; Luo, Y.; Guo, H.; Jiang, R.-D.; Liu, M.-Q.; Chen, Y.; Shen, X.-R.; Wang, X.; Zheng, X.-S.; Zhao, K.; Chen, Q.-J.; Deng, F.; Liu, L.-L.; Yan, B.; Zhan, F.-X.; Wang, Y.-Y.; Xiao, G.-F.; Shi, Z.-L., A Pneumonia Outbreak Associated with a New Coronavirus of Probable Bat Origin. Nature 2020, 579 (7798), 270-273.

9. Schoeman, D.; Fielding, B. C., Coronavirus envelope protein: current knowledge. Virology 2019, 16 (1), 69.

10. Fauquet, C. M.; Fargette, D., International Committee on Taxonomy of Viruses and the 3,142 unassigned species. Virology 2005, 2 (1), 64.

11. Zhang, L.; Lin, D.; Sun, X.; Curth, U.; Drosten, C.; Sauerhering, L.; Becker, S.; Rox, K.; Hilgenfeld, R., Crystal Structure of SARS-CoV-2 Main Protease Provides a Basis for Design of Improved $\alpha$-Ketoamide Inhibitors. Science 2020, 368, 409-412.

12. Jin, Z.; Zhao, Y.; Sun, Y.; Zhang, B.; Wang, H.; Wu, Y.; Zhu, Y.; Zhu, C.; Hu, T.; Du, X.; Duan, Y.; Yu, J.; Yang, X.; Yang, X.; Yang, K.; Liu, X.; Guddat, L. W.; Xiao, G.; Zhang, L.; Yang, H.; Rao, Z., Structural basis for the inhibition of SARS-CoV-2 main protease by antineoplastic drug carmofur. Nat Struct Mol Biol 2020.

13. Dai, W.; Zhang, B.; Su, H.; Li, J.; Zhao, Y.; Xie, X.; Jin, Z.; Liu, F.; Li, C.; Li, Y.; Bai, F.; Wang, H.; Cheng, X.; Cen, X.; Hu, S.; Yang, X.; Wang, J.; Liu, X.; Xiao, G.; Jiang, H.; Rao, Z.; Zhang, L.-K.; Xu, Y.; Yang, H.; Liu, H., Structure-based design of antiviral drug candidates targeting the SARS-CoV-2 main protease. Science 2020, eabb4489.

14. Ngo, S. T.; Quynh Anh Pham, N.; Thi Le, L.; Pham, D.H.; Vu, V. V., Computational Determination of Potential Inhibitors of SARS-CoV-2 Main Protease. J. Chem. Inf. Model. 2020.

15. Abd Al-Aziz A., A.-S.; Ibrahim, A.; Arpita, Y.; Raymond A., P., Computational Design of Potent Inhibitors for SARS-CoV2's Main Protease. 2020.

16. Muhammet, K., Pharmacophore Analyses of SARS-CoV2 Active Main Protease Inhibitors Using Pharmacophore Query and Docking Study. 2020.

17. Gao, K.; Nguyen, D. D.; Chen, J.; Wang, R.; Wei, G.-W., Repositioning of 8565 Existing Drugs for COVID-19. J. Phys. Chem. Lett 2020, 5373-5382.

18. Marshall, G. R., Computer-Aided Drug Design. Ann. Rev. Pharmacol. Toxicol. 1987, 27, 193-213. 
19. Homeyer, N.; Stoll, F.; Hillisch, A.; Gohlke, H., Binding Free Energy Calculations for Lead Optimization: Assessment of Their Accuracy in an Industrial Drug Design Context. J. Chem. Theory Comput. 2014, 10 (8), 3331-3344.

20. Mai, N. T.; Lan, N. T.; Vu, T. Y.; Mai Duong, P. T.; Tung, N. T.; Thu Phung, H. T., Estimation of the Ligand-Binding Free Energy of Checkpoint kinase 1 via Non-equilibrium MD Simulations. J. Mol. Graph. Modell. 2020, 107648.

21. Tran, P.-T.; Hoang, V.-H.; Lee, J.; Hien, T. T. T.; Tung, N. T.; Ngo, S. T., In vitro and in silico determination of glutaminyl cyclase inhibitors. RSC Adv 2019, 9 (51), 29619 . 29627.

22. Yu, W.; MacKerell, A. D., Computer-Aided Drug Design Methods. In Antibiotics: Methods and Protocols, Sass, P., Ed. Springer New York: New York, NY, 2017; pp 85-106.

23. Sterling, T.; Irwin, J. J., ZINC 15--Ligand Discovery for Everyone. J. Chem. Inf. Model. 2015, 55 (11), 2324-2337.

24. Kim, S.; Thiessen, P. A.; Bolton, E. E.; Chen, J.; Fu, G.; Gindulyte, A.; Han, L.; He, J.; He, S.; Shoemaker, B. A.; Wang, J.; Yu, B.; Zhang, J.; Bryant, S. H., PubChem Substance and Compound databases. Nucleic Acids Res. 2016, 44 (D1), D1202D1213.

25. Trott, 0.; Olson, A. J., Improving the Speed and Accuracy of Docking with a New Scoring Function, Efficient Optimization, and Multithreading. J. Comput. Chem. 2010, 31, 455-461.

26. Nguyen, N. T.; Nguyen, T. H.; Pham, T. N. H.; Huy, N. T.; Bay, M. V.; Pham, M. Q.; Nam, P. C.; Vu, V. V.; Ngo, S. T., Autodock Vina Adopts More Accurate Binding Poses but Autodock4 Forms Better Binding Affinity. J. Chem. Inf.Model. 2020, 60 (1), 204-211.

27. Abraham, M. J.; Murtola, T.; Schulz, R.; Páll, S.; Smith, J. C.; Hess, B.; Lindahl, E., GROMACS: High Performance Molecular Simulations through Multi-Level Parallelism from Laptops to Supercomputers. SoftwareX 2015, 1-2, 19-25.

28. Aliev, A. E.; Kulke, M.; Khaneja, H. S.; Chudasama, V.; Sheppard, T. D.; Lanigan, R. M., Motional Timescale Predictions by Molecular Dynamics Simulations: Case Study using Proline and Hydroxyproline Sidechain Dynamics. Proteins: Struct., Funct., Bioinf. 2014, 82 (2), 195-215.

29. Jorgensen, W. L.; Chandrasekhar, J.; Madura, J. D.; Impey, R. W.; Klein, M. L., Comparison of Simple Potential Functions for Simulating Liquid Water. J. Chem. Phys. 1983, 79 (2), 926-935.

30. Wang, J.; Wang, W.; Kollman, P. A.; Case, D. A., Automatic Atom Type and Bond Type Perception in Molecular Mechanical Calculations. J Mol Graph Model 2006, 25 (2), 247260.
31. Case, D. A.; Ben-Shalom, I. Y.; Brozell, S. R.; Cerutti, D. S.; Cheatham, T. E. C., III, V.W.D. ; Darden, T. A.; Duke, R. E.; Ghoreishi, D.; Gilson, M. K.; Gohlke, H.; Goetz, A. W.; Greene, D.; Harris, R.; Homeyer, N.; Huang, Y.; Izadi, S.; Kovalenko, A.; Kurtzman, T.; Lee, T. S.; LeGrand, S.; Li, P.; Lin, C.; Liu, J.; Luchko, T.; Luo, R.; Mermelstein, D. J.; Merz, K. M.; Miao, Y.; Monard, G.; Nguyen, C.; Nguyen, H.; Omelyan, I.; Onufriev, A.; Pan, F.; Qi, R.; Roe, D. R.; Roitberg, A.; Sagui, C.; SchottVerdugo, S.; Shen, J.; Simmerling, C. L.; Smith, J.; SalomonFerrer, R.; Swails, J.; Walker, R. C.; Wang, J.; Wei, H.; Wolf, R. M.; Wu, X.; Xiao, L.; D.M., Y.; P.A., a. K., AMBER 18. University of California, San Francisco 2018.

32. Sousa da Silva, A. W.; Vranken, W. F., ACPYPE AnteChamber PYthon Parser interfacE. BMC Research Notes 2012, 5 (1), 1-8.

33. Wang, J.; Wolf, R. M.; Caldwell, J. W.; Kollman, P. A.; Case, D. A., Development and Testing of a General Amber Force Field. J. Comput. Chem. 2004, 25 (9), 1157-1174.

34. Zhang, H.; Yin, C.; Jiang, Y.; van der Spoel, D., Force Field Benchmark of Amino Acids: I. Hydration and Diffusion in Different Water Models. J. Chem. Inf. Model. 2018, 58 (5), 1037 1052.

35. Zhang, H.; Jiang, Y.; Cui, Z.; Yin, C., Force Field Benchmark of Amino Acids. 2. Partition Coefficients between Water and Organic Solvents. J. Chem. Inf. Model. 2018, 58 (8), 1669-1681.

36. Ngo, S. T.; Hung, H. M.; Nguyen, M. T., Fast and Accurate Determination of the Relative Binding Affinities of Small Compounds to HIV-1 Protease using Non-Equilibrium Work. J. Comput. Chem. 2016, 37 (31), 2734-2742.

37. Ngo, S. T.; Nguyen, M. T.; Nguyen, M. T., Determination of the absolute binding free energies of HIV-1 protease inhibitors using non-equilibrium molecular dynamics simulations. Chem. Phys. Lett. 2017, 676, 12-17.

38. Efron, B., Bootstrap Methods: Another Kook at the Jackknife. Ann. Stat. 1979, 7, 1-26.

$39 . \quad$ Ngo, S. T.; Huong, L. T. T.; Quan, P. M.; Tung, N. T.; Vu, V. V., Estimating Potential Inhibitors for SARS-CoV-2 Mpro from Available Drugs via Docking and Perturbation Calculations. 2020.

40. Ngo, S. T.; Fang, S.-T.; Huang, S.-H.; Chou, C.-L.; Huy, P. D. Q.; Li, M. S.; Chen, Y.-C., Anti-Arrhythmic Medication Propafenone a Potential Drug for Alzheimer's Disease Inhibiting Aggregation of $\mathrm{A} \beta$ : In Silico and In Vitro Studies. J. Chem. Inf. Model. 2016, 56 (7), 1344-1356.

41. Tam, N. M.; Vu, K. B.; Vu, V. V.; Ngo, S. T., Influence of various force fields in estimating the binding affinity of acetylcholinesterase inhibitors using fast pulling of ligand scheme. Chem. Phys. Lett. 2018, 701, 65-71. 


\begin{tabular}{|c|c|c|}
\hline $\begin{array}{c}\text { Son Tung Ngo, } \\
\text { Khanh B. Vu, T. } \\
\text { Ngoc Han Pham, Le } \\
\text { Thi Thuy Huong, } \\
\text { Pham Minh Quan, } \\
\text { Linh Hoang Tran, } \\
\text { Nguyen Thanh } \\
\text { Tung, Van V. Vu, } \\
\text { Trung Hai Nguyen }\end{array}$ & $\begin{array}{c}\text { Rapid Prediction of Possible } \\
\text { Inhibitors for SARS-CoV-2 Main } \\
\text { Protease using Docking and } \\
\text { FPL Simulations }\end{array}$ \\
\hline
\end{tabular}

